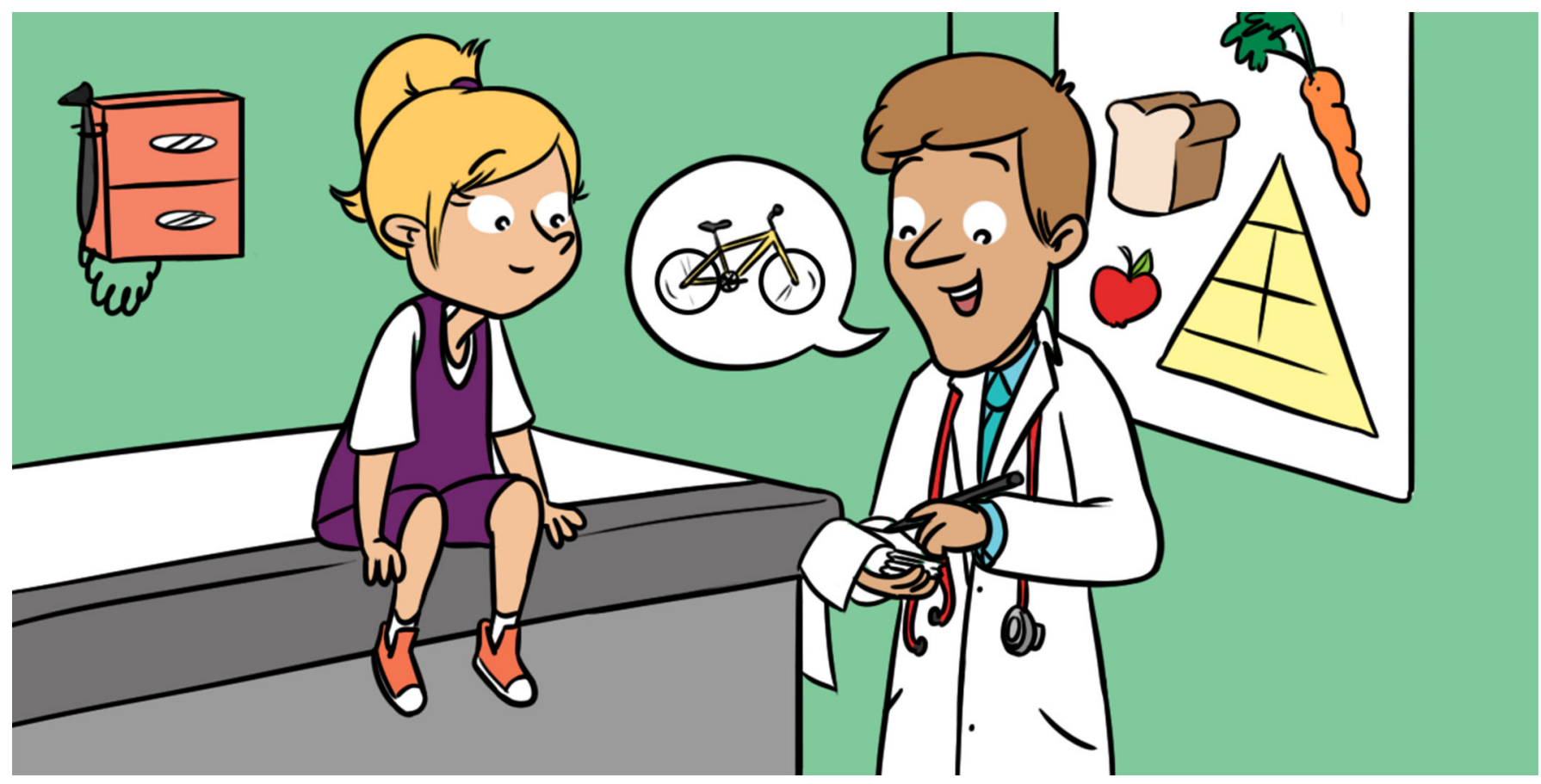

\title{
MUSCLING UP ON MENTAL ILLNESS: HOW EXERCISE CAN HELP BOTH BODY AND MIND
}

\section{Grace McKeon ${ }^{1}$ and Simon Rosenbaum ${ }^{1,2 *}$}

1 School of Psychiatry, University of New South Wales, Sydney, NSW, Australia

Black Dog Institute, Sydney, NSW, Australia

YOUNG REVIEWERS:

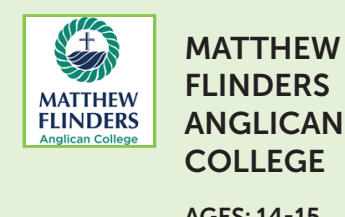

We know that regular exercise is important for maintaining a healthy body and for reducing the risk of developing chronic diseases, like heart disease and diabetes. Interestingly, the importance of exercise in maintaining a healthy mind is also becoming more and more clear. Exercise is now being prescribed by doctors as a part of treatment for a range of mental illnesses, including depression and anxiety. While scientists do not fully understand how exercise can help improve our mood, we know enough about the positive benefits of exercise to suggest that everyone living with mental illness should have access to tailored exercise programs as part of their recovery.

\section{EXERCISE}

You have heard it all before; get off your phone, stop watching TV, and go play outside, you couch potato! Are your parents and teachers just wasting their breath, or is there actually some science behind 


\section{EXERCISE}

Structured subset of physical activity that is planned and deliberate.

\section{MENTAL HEALTH}

Someones psychological and emotional wellbeing.

\section{MENTAL ILLNESS}

A group of illnesses that affects the mind for example, depression and anxiety. this advice? Let us take a look at some of the exciting research on how exercise can improve both physical and mental health.

How do you feel when you exercise regularly? Do you feel stronger? Fitter? More flexible? Exercise is known to help improve your cardiovascular system (your heart and lungs), to help you develop healthy bones, muscles, and joints, and help you maintain a healthy weight. Exercise has also been shown to help prevent and manage several chronic diseases, such as diabetes and heart disease.

Those are the benefits of exercise that you have probably already heard of. But how does your mind feel after you exercise? Do you feel happier? Can you think more clearly? Do you find it easier to fall asleep? Have a think about it and we will come back to this.

\section{WHAT IS MENTAL ILLNESS?}

Just like our bodies can get sick from time to time (like when we have a sore throat), so too can parts of our brain that control how we feel. This type of illness is called mental illness. Just like the phrase "cardiovascular disease" is used to describe a group of diseases that affect the heart, you can think of mental illness as broad term used to describe diseases that affect the mind. Mental illness includes a range of conditions you might have heard of, including depression and anxiety.

Everybody experiences a range of feelings that come and go; nervous, happy, lonely, excited, or angry. Sometimes the bad feelings do not go away and can start to impact important parts of our lives, such as the ability to perform at school or at work. Because we cannot see mental illness in quite the same way that we see physical illness or injury (like a broken leg), people sometimes find mental illness difficult to talk about. Even though we cannot "see" mental illness in the same way we can see a broken leg, it is important to remember that, just like a broken bone, with the right treatment and support, people can recover from a mental illness and live happy, healthy lives.

Mental illness is common and in Australia and affects around one in five people in any 1 year and $45 \%$ of the population at some point during their lifetime. Unlike many other health conditions, such as heart disease or arthritis, the risk of developing a mental illness does not increase with age. In fact, the first onset of a mental illness typically occurs in childhood or adolescence, with half of all cases of mental illness starting by the age of 14 and three quarters by age 24 [1]. It is estimated that $13.9 \%$ of children aged 4-17 experience a mental illness [2]. 
PHYSICAL ACTIVITY

Any bodily movement produced by skeletal muscles that requires energy expenditure.
Given how many people experience mental illness, finding new ways of treating and preventing mental illness is extremely important.

It is also important to understand the difference between mental health and mental illness. You do not have to have a diagnosed mental illness to experience poor mental health. For example, the diagram below shows how mental health and mental illness can be separate.

Just like physical illnesses, people experiencing mental illness often find it harder to engage in exercise and, on average, spend more time sedentary (sitting or lying down), which we know is bad for our health. Think about when you have felt upset or down. Did you find it harder to find the motivation to do things like socialize or walk the dog? Even in the general population, motivation to exercise is low, with only $35 \%$ of the population getting the recommended amount of physical activity. So, it is not surprising that people with mental illness often even less likely to be active.

Think of it like this, our mental health and our physical health are connected. It can be difficult to have one without the other. Often, someone experiencing mental illness will also experience poor physical health, and poor physical health can in turn be associated with poor mental health.

\section{EXERCISE AS A TREATMENT FOR MENTAL ILLNESS}

We now know that exercise can be a really important part of care for people living with short- and long-term mental illness [3]. Exercise can improve mood and reduce symptoms of mental illness, including depression and anxiety. Exercise can also improve sleep quality, increase energy levels and reduce stress. Exercise has also been shown to increase self-confidence and improve both memory and concentration. Plus, exercise offers all these benefits without the risk of serious side-effects. It has been said that, if exercise were a pill, it would be prescribed to every patient by every doctor.

The benefits of exercise are "transdiagnostic," meaning that regardless of which mental illness someone may be experiencing, everyone can still gain some benefits from exercise. The benefits may differ a little depending on the symptoms experienced. For example, for someone with depression, exercise may help to improve sleep quality or help provide motivation to get out of bed, while for someone experiencing anxiety symptoms, exercise may act as a distraction from constant worry. 


\section{HOW CAN EXERCISE HELP?}

The mechanisms by which exercise reduces the symptoms of mental illness are not fully understood. We do know that exercise may provide a sense of enjoyment and fulfillment. Exercise can enhance self-efficacy (belief in our own abilities) and self-esteem (how we feel about ourselves) by helping us master new skills. Exercise can also be a great opportunity to make friends, whether it is in a dance class or on a soccer team.

In terms of the biological mechanisms, exercise has been shown to cause changes in certain chemicals called endorphins. Endorphins are the "feel good" chemical messengers that help relieve pain and stress during exercise. Exercise also stimulates the release of other chemicals called dopamine, norepinephrine, and serotonin. Sounds fancy but what does that mean? Well, these brain chemicals play an important part in regulating your mood. In fact, they are the same chemicals that are targeted by medications for mental illness. Exercise also helps to reduce the levels of a stress hormone called cortisol, so that we feel less stressed out.

Another important chemical is brain-derived neurotrophic factor, or BDNF. Think of it like "a fertilizer for your brain." BDNF is a protein in your brain that helps to maintain the life of your brain cells and helps you to grow new ones. Low levels of BDNF have been seen in people with mental illness like depression and anxiety. What is the good news? Exercise can also increase the brain's BDNF levels, which helps improve brain function, mood stability and general well-being [4]. Is there anything exercise cannot do?

Finally, exercise can also be used as a form of exposure therapy. Think about the feelings you experience when you feel stressed. Your body tenses, your heart races, you sweat, you become short of breath. Interestingly, these are the same feelings you can experience when you work up a sweat exercising. Exercise is therefore another way to expose people to anxiety symptoms, but in a safe and controlled manner that can help people become less sensitive to these symptoms and help with recovery from anxiety.

\section{SO, WHAT NOW?}

Knowing all these benefits is good, but if we do not change the way we treat mental illness to ensure that exercise is included as a part of treatment, and then the science alone is unlikely to help anyone. While many countries now include exercise as part of mental illness 
Figure 1

Mental health continuum. Mental health and mental illness are two distinct things.

For example, someone with a diagnosed mental illness may be recovering well and experiencing positive mental health, while someone with no diagnosable mental illness may be experiencing poor mental health at any one point in time.

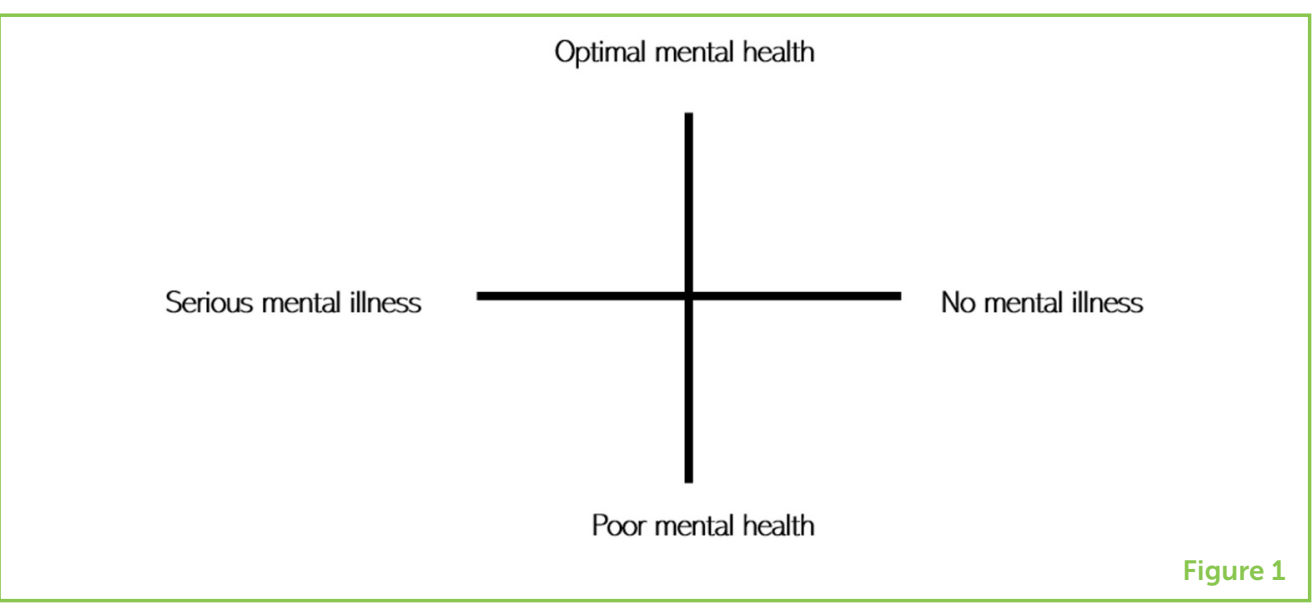

treatment, we still have a long way to go in terms of breaking down the divide between physical and mental health care. While exercise is not a replacement for medication or other treatments, it can clearly be an important and useful part of the treatment of mental illness.

We have spoken a lot about the benefits of exercise for people experiencing mental illness, but the thing about exercise is it can make you feel better even if you are already feeling okay. Think back to Figure 1. Everyone finds themselves somewhere on the mental health-mental illness continuum, and it is important to know you do not need to have a mental illness to experience the benefits of exercise. One large study combining data from all around the world showed that exercising can reduce your chances of developing depression by up to $17 \%$ [5]!

That being said, how much exercise should you be doing and what type is best? The Australian guidelines recommend that 5-12 years-old need 60 min of moderate to vigorous physical activity every day. Unfortunately, only one third of children meet these recommendations and it is even worse for adults. If you are not currently meeting these guidelines, increasing your activity gradually is the most achievable way. Even one exercise session a week can have great benefits for your mental and physical health. As we have said above, there are many types of exercise that can provide mental health benefits, not just running on a treadmill or lifting weights. You might prefer chasing friends, riding a bike, shooting basketball hoops, or dancing. Finding a type of exercise that you enjoy is critical. The benefits of exercise can occur regardless of the type of exercise.

Childhood through young adulthood is a really important time for our development and it lays the foundation for the rest of our lives, both physically and mentally. Think for a moment about your school PE classes. Is the thought enough to make you shudder? A new study found that the way we feel during gym classes at school can shape the way we feel about 
exercise in the future and whether we choose to be physically active [6]. There are many reasons why so many people are inactive, but most behavioral scientists agree that our attitudes about exercise play a defining role in whether or not we are physically active. If we expect exercise to be fun and enjoyable, often we will exercise. If we do not think exercise will be enjoyable, we would not. Simple as that. Therefore, establishing healthy habits and positive attitudes toward exercise at a young age is important. So, if you do not like PE class, it is about finding what you do enjoy and doing it regularly. Remember, our bodies are made to move. So, go on! Stop reading this boring old paper, grab a friend, and get moving.

\section{REFERENCES}

1. Kessler, R. C., Berglund, P., Demler, O., Jin, R., Merikangas, K. R., and Walters, E. E. 2005. Lifetime prevalence and age-of-onset distributions of DSM-IV disorders in the National Comorbidity Survey Replication. Arch. Gen. Psychiatry 62:593-602. doi: 10.1001/archpsyc.62.6.593

2. The Mental Health of Children and Adolescents. 2015. Report on the Second Australian Child and Adolescent Survey of Mental Health and Wellbeing. Available online at: www.health.gov.au

3. Rosenbaum, S., Tiedemann, A., Sherrington, C., Curtis, J., and Ward, P. B. 2014. Physical activity interventions for people with mental illness: a systematic review and meta-analysis. J. Clin. Psychiatry 75:964-74. doi: 10.4088/JCP.13r08765

4. Schuch, F. B., Deslandes, A. C., Stubbs, B., Gosmann, N. P., Silva, C. T., and Fleck, M. P. 2016. Neurobiological effects of exercise on major depressive disorder: a systematic review. Neurosci. Biobehav. Rev. 61:1-11. doi: 10.1016/j. neubiorev.2015.11.012

5. Schuch, F. B., Vancampfort, D., Firth, J., Rosenbaum, S., Ward, P. B., Silva, E. S., et al. 2018. Physical activity and incident depression: a meta-analysis of prospective cohort studies. Am. J. Psychiatry 175:631-48. doi: 10.1176/appi. ajp.2018.17111194

6. Ladwig, M. A., Vazou, S., and Ekkekakis, P. 2018. "My best memory is when i was done with it": PE memories are associated with adult sedentary behavior. Transl. J. Am. Coll. Sports Med. 3:119-29. doi: 10.1249/TJX.0000000000000067

SUBMITTED: 24 September 2018; ACCEPTED: 15 February 2019; PUBLISHED ONLINE: 11 March 2019.

EDITED BY: Daniel F. Hermens, University of the Sunshine Coast, Australia

CITATION: McKeon G and Rosenbaum S (2019) Muscling Up on Mental Illness: How Exercise Can Help Both Body and Mind. Front. Young Minds 7:35. doi: 10.3389/ frym.2019.00035 
CONFLICT OF INTEREST STATEMENT: The authors declare that the research was conducted in the absence of any commercial or financial relationships that could be construed as a potential conflict of interest.

COPYRIGHT (c) 2019 McKeon and Rosenbaum. This is an open-access article distributed under the terms of the Creative Commons Attribution License (CC BY). The use, distribution or reproduction in other forums is permitted, provided the original author(s) and the copyright owner(s) are credited and that the original publication in this journal is cited, in accordance with accepted academic practice. No use, distribution or reproduction is permitted which does not comply with these terms.

\section{YOUNG REVIEWERS}
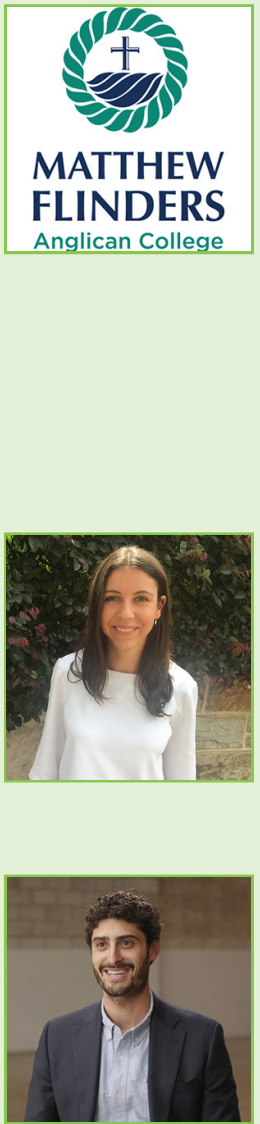

\section{MATTHEW FLINDERS ANGLICAN COLLEGE, AGES: 14-15}

Matthew Flinders Anglican College young reviewers are keen budding scientists who enjoy taking on challenges. They are a collaborative bunch of young minds, with shared interests in science, music, and sport. This group of young reviewers thoroughly enjoys being part of Frontiers for Young Minds and is excited to be involved in how science is being communicated and shaped.

\section{AUTHORS}

\section{GRACE MCKEON}

I am an Exercise Physiologist and Researcher at the University of New South Wales in Sydney Australia. My research looks at the benefits of physical activity on our mental health and how we can implement this in the real world. Outside of work, I love playing team sports and being outdoors.

\section{SIMON ROSENBAUM}

I am a Senior Research Fellow in the School of Psychiatry, UNSW Sydney and the Black Dog Institute. My research looks at the impact of physical activity on symptoms of mental illness and the use of exercise as a part of the standard care within mental health settings. I enjoy cycling, kayaking, rock climbing, and generally any type of physical activity, ideally outside. *s.rosenbaum@unsw.edu.au 